Article

\title{
Reprocessable, Reworkable, and Mechanochromic Polyhexahydrotriazine Thermoset with Multiple Stimulus Responsiveness
}

\author{
Li Chen ${ }^{1,2}$, Siyao Zhu ${ }^{1,2}$, Innocent Toendepi ${ }^{1}$, Qiuran Jiang ${ }^{2}$, Yi Wei ${ }^{1,2} \oplus$, Yiping Qiu ${ }^{2}$ and \\ Wanshuang Liu 1,2,*(D) \\ 1 Shanghai Collaborative Innovation Center for High Performance Fiber Composites, \\ Center for Civil Aviation Composites, Donghua University, 2999 North Renmin Road, \\ Shanghai 201620, China; 2180072@mail.dhu.edu.cn (L.C.); 2180138@mail.dhu.edu.cn (S.Z.); \\ muvinnot@icloud.com (I.T.); weiy@dhu.edu.cn (Y.W.) \\ 2 Key Laboratory of Textile Science \&Technology, Ministry of Education, College of Textiles, \\ Donghua University, 2999 North Renmin Road, Shanghai 201620, China; jj@dhu.edu.cn (Q.J.); \\ ypqiu@dhu.edu.cn (Y.Q.) \\ * Correspondence: wsliu@dhu.edu.cn
}

Received: 29 September 2020; Accepted: 13 October 2020; Published: 15 October 2020

\begin{abstract}
Developing recyclable, reworkable, and intelligent thermosetting polymers, as a longstanding challenge, is highly desirable for modern manufacturing industries. Herein, we report a polyhexahydrotriazine thermoset (PHT) prepared by a one-pot polycondensation between 4-aminophenyl disulfide and paraformaldehyde. The PHT has a glass transition temperature of $135^{\circ} \mathrm{C}$ and good solvent resistance. The incorporation of dual stimuli-responsive groups (disulfide bond and hexahydrotriazine ring) endows the PHT with re-processability, re-workability, and damage monitoring function. The PHT can be repeatedly reprocessed by hot pressing, and a near $100 \%$ recovery of flexural strength is achieved. The PHT can also degrade in inorganic acid or organic thiol solutions at room temperature. The thermally reworkable test demonstrates that, after heating the PHT at $200{ }^{\circ} \mathrm{C}$ for $1 \mathrm{~h}$, the residuals can be easily wiped off. Finally, the PHT exhibits a reversible mechanochromic behavior when damaged.
\end{abstract}

Keywords: polyhexahydrotriazine; vitrimers; recyclability; disulfide bonds

\section{Introduction}

Thermosetting polymers have widespread industrial applications such as structural adhesives, protective coatings, electronic packaging materials, and polymer matrices for advanced composites thanks to their remarkable mechanical and electrical performances as well as excellent heat, creep, and chemical resistance. However, conventional thermosetting polymers have permanent cross-linked structures consisting of irreversible covalent bonds, making them extremely difficult for recycling [1-3]. Currently, technological innovations greatly shorten the iterative circles of consumer products, especially for personal electronic equipment in which thermosetting polymers are largely used. Along with stricter environmental regulations, the intractability of thermosetting polymers has raised increasing concerns about disposal and recycling of discarded electronics and composite products. Besides recyclability, reworkable thermosetting polymers, which can be removed during the manufacturing process, are also desirable [2,4]. For example, it is a high cost to discard an assembled electronic component with only one faulty chip. The use of reworkable thermosetting polymers for electronic encapsulation will allow removal of an individual chip from the printed circuit board for replacement or 
repair. Therefore, both economic and environmental factors are driving the development of recyclable and/or reworkable thermosetting polymers.

Over the past two decades, incorporating dynamic covalent bonds has become an attractive avenue to endow thermosetting polymers with recyclability [5-8]. Such thermosetting polymers, which are often defined as covalent adaptable networks (CANs) or vitrimers, can be reprocessed, repaired, or degraded under certain external stimuli (such as heat, $\mathrm{pH}$, light, solvent, etc.) through the reversible depolymerization or exchange reactions of their dynamic cross-links [3,9-11]. So far, a number of CANs based on Michael addition [12-14], Diels-Alder reaction [15,16], disulfide exchange [17-19], imine metathesis [20-22], transesterification [23-25], olefin metathesis [26,27], silyl ether transalkoxylation $[28,29]$, diketoenamine exchange [30,31], and dioxaborolane metathesis $[32,33]$ have been proposed in the literature. Besides recyclability, many other adaptive properties of CANs were also investigated, such as reconfigurability [34,35], shape memory [36,37], and network topological transformation $[18,25,38]$.

In general, reworkable thermosetting polymers contain the cleavable linkages, which can decompose under certain conditions such as specific reagents or heating [2]. Therefore, it is feasible to obtain recyclable and reworkable thermosetting polymers with multiple stimulus responsiveness by introducing dynamic and labile covalent bonds simultaneously. It was reported that polyhexahydrotriazine thermosets (PHTs) have the advantages of easy preparation, high mechanical performances, and degradability in mild acidic solutions [39-41]. Herein, a novel PHT was designed and prepared by a one-pot and catalyst-free polycondensation between 4-aminophenyl disulfide and paraformaldehyde (PFA). We choose to incorporate disulfide bonds into the PHT because the chemistry of disulfides is very versatile. Disulfide bonds can undergo reversible thiol-disulfide exchange and disulfide exchange by heat, UV, or catalysts [42-45]. Especially, the aromatic disulfides have the advantage of low activation energy to facilitate these exchange reactions under a moderate condition [42,46]. Disulfide bonds are also regarded as thermally cleavable linkages due to their low bond dissociation energy $(210-270 \mathrm{~kJ} / \mathrm{mol})[47,48]$. More interestingly, the incorporation of disulfide bonds can bring about the mechanochromic effect for thermosetting polymers [49]. To verify our hypothesis, the recyclability, reworkability, and mechanochromic behaviors of the prepared disulfide-containing PHT were investigated in the following study.

\section{Materials and Methods}

\subsection{Materials}

PFA, acetone, anhydrous ethanol, chloroform, tetrahydrofuran (THF), N-methyl-2-pyrrolidone (NMP), dimethyformamide (DMF), hydrochloric acid $(\mathrm{HCl}, 36 \%)$, and sodium hydroxide $(\mathrm{NaOH})$ were purchased from Sinopharm Chemical Reagent Co., Ltd., Shanghai, China. 4-aminophenyl disulfide and 2-mercaptoethanol were purchased from Shanghai Taitan Technology Co., Ltd., Shanghai, China. All the chemicals were used as received without further purification.

\subsection{Preparation of $P H T$}

Under magnetic stirring, PFA (60.0 mmol), distilled water $(3.0 \mathrm{~mL})$, and NMP $(27.0 \mathrm{~mL})$ were added into a flask and heated at $80^{\circ} \mathrm{C}$ for $0.5 \mathrm{~h}$. When the obtained solution was cooled down to $50{ }^{\circ} \mathrm{C}, 4$-aminophenyl disulfide $(24 \mathrm{mmol}$ ) was introduced and stirred for $1 \mathrm{~h}$. Then, the prepolymer solution was poured into a polytetrafluoroethylene mold lined with a layer of aluminum foil, which was followed by removing the solvent and staged precuring at $50^{\circ} \mathrm{C}$ for $6 \mathrm{~h}, 80^{\circ} \mathrm{C}$ for $2 \mathrm{~h}$, and $120^{\circ} \mathrm{C}$ for $2 \mathrm{~h}$. After that, the B-stage polymer film was peeled from the aluminum foil and grinded into fine powders. The obtained powders were heated at $120^{\circ} \mathrm{C}$ for $4 \mathrm{~h}$ under reduced pressure to remove excess NMP. In order to prepare the PHT specimens with no bubbles (from evaporation of the residue NMP solvent), the dry powders were placed into the steel punch molds with specific dimensions and pressed at $150^{\circ} \mathrm{C}$ under $0.3 \mathrm{MPa}$ for $1 \mathrm{~h}$. After cooling to room temperature, the obtained PHT 
specimens were polished for thermal and mechanical tests. The above preparation procedures for the PHT are illustrated in Figure 1b.
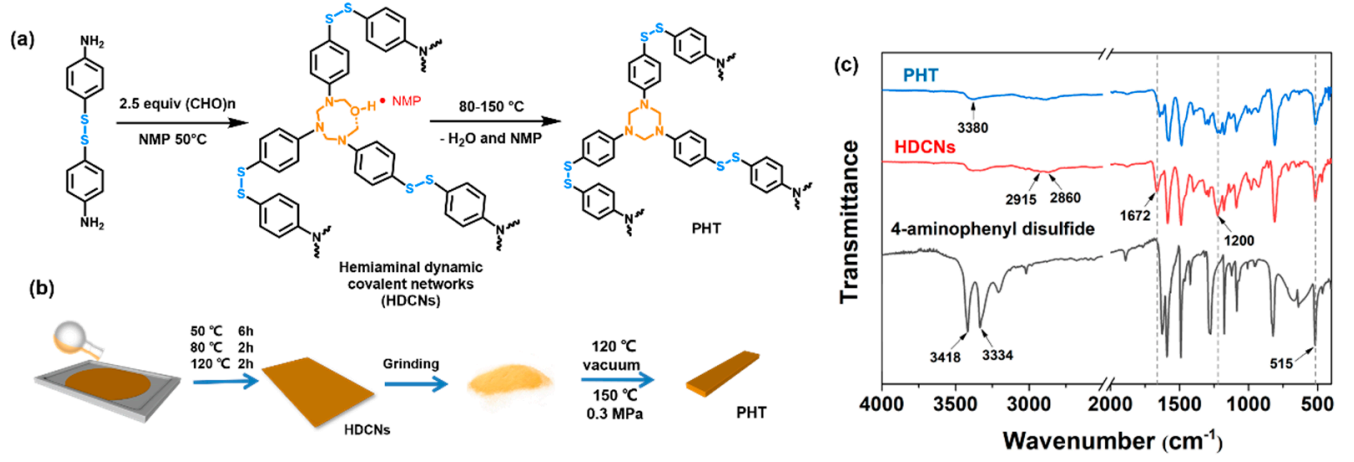

Figure 1. (a) The synthetic route of the polyhexahydrotriazine thermosets (PHT). (b) Preparation process of PHT bars. (c) FTIR spectra of hemiaminal dynamic covalent networks (HDCNs) and PHT.

\subsection{Reprocessing of PHT}

The cured PHT was first grinded into fine powders, and placed into a steel punch mold. Then, the PHT powders was pressed at $150^{\circ} \mathrm{C}$ under $0.3 \mathrm{MPa}$ for $1 \mathrm{~h}$. After cooling and demoulding, defect-free PHT specimens were obtained. This reprocessing treatment was repeated twice.

\subsection{Chemical Reworkability}

Chemical degradation of the PHT was performed in acid and thiol solutions, respectively. Typically, a piece of PHT film (about $300 \mathrm{mg}$ ) was placed into $15 \mathrm{~mL}$ of $\mathrm{HCl}(1 \mathrm{M})$ or $15 \mathrm{~mL}$ 2-mercaptoethanol/DMF $(0.1 \mathrm{M})$ solutions, which was followed by standing for $24 \mathrm{~h}$.

\subsection{Thermal Reworkability}

The prepolymer solution in Section 2.2 was poured onto a glass slide and heated at $50{ }^{\circ} \mathrm{C}$ for $6 \mathrm{~h}, 80^{\circ} \mathrm{C}$ for $2 \mathrm{~h}, 120^{\circ} \mathrm{C}$ for $2 \mathrm{~h}$, and $150^{\circ} \mathrm{C}$ for $1 \mathrm{~h}$. The obtained PHT cured on the glass slide was thermally degraded at $200^{\circ} \mathrm{C}$ for $1 \mathrm{~h}$ in an oven. The degradation products were removed from the glass slide by a clean cloth soaked by acetone.

\subsection{Characterizations}

Fourier transform infrared spectroscopy (FTIR) was carried out on a Nicolet 6700 FTIR spectrometer using the attenuated total reflection (ATR) mode with a scan range from 400 to $4000 \mathrm{~cm}^{-1}$. Dynamic mechanical analysis (DMA) was performed on a TA Instruments DMA Q800 with a heating rate of $3{ }^{\circ} \mathrm{C} \mathrm{min}-1$ and a frequency of $1 \mathrm{~Hz}$. Double cantilever mode was used for the DMA tests and the specimen dimension was $60 \times 15.0 \times 2.0 \mathrm{~mm}^{3}$. Stress-relaxation tests were also performed on a TA Instruments DMA Q800. The tests were carried out using the tensile mode with rectangular specimens $\left(12.0 \times 6.0 \times 1.0 \mathrm{~mm}^{3}\right)$. The specimen was aligned by preloading $10^{-3} \mathrm{~N}$ force and thermally equilibrated for $10 \mathrm{~min}$ at each test temperature. The data of relaxation modulus versus time were recorded. Flexural tests, which followed the ASTM D790-03 standard, were performed on the Wance ETM104B-EX electronic universal testing machine with a $2000 \mathrm{~N}$ load cell at a crosshead speed of $1 \mathrm{~mm} \mathrm{~min}{ }^{-1}$. Each reported value was the average of at least three valid specimens. Thermal gravimetric analysis (TGA) was conducted on a TA Instruments TGA Q 500 using nitrogen as the purge gas at a heating rate of $10^{\circ} \mathrm{C} \mathrm{min}^{-1}$ from 50 to $800^{\circ} \mathrm{C}$. 


\section{Results}

\subsection{Preparation of PHT}

First, hemiaminal dynamic covalent networks (HDCNs) were synthesized by a water-catalyzed stepwise condensation of 4-aminophenyl disulfide with PFA at $50^{\circ} \mathrm{C}$ [39]. The HDCNs were further cyclized at high temperature to yield the PHT (Figure 1a). Similar to the reported method by Yuan et al. [41], the specimens for thermal and mechanical tests were prepared as illustrated in Figure $1 \mathrm{~b}$. Since both the disulfide bond and hemiaminal group are dynamic covalent bonds [50,51], uniform coherent PHT bars could be obtained by pressing HDCN powders at $150{ }^{\circ} \mathrm{C}$ under $0.3 \mathrm{MPa}$ for $1 \mathrm{~h}$. It should be noted that the PHT specimens were prepared by a hot-press process rather than direct curing in a mold. This is because there exists a high boiling point NMP solvent in the monomer mixture. If the mixture is directly cured in a mold, this would generate bubbles in the PHT specimens owing to evaporation of the residue NMP solvent. Considering that the introduced dynamic disulfide bonds can endow the PHT with re-processability [50]. A hot-press process was used to prepare the PHT specimens with high quality. The PHT formation was characterized by FTIR. Figure 1c shows the FTIR spectrum of HDCNs after precuring. Compared with the FTIR spectrum of 4-aminophenyl disulfide, the new band at $1200 \mathrm{~cm}^{-1}$ is assigned to the C-N stretching vibration in the hemiaminal group. The bands at 2860 and $2915 \mathrm{~cm}^{-1}$ can be attributed to asymmetric and symmetry stretching vibration from the -CH2- on the hexatomic ring. The characteristic bands of primary amine ( 3300 and $3190 \mathrm{~cm}^{-1}$ ) in 4-aminophenyl disulfide no longer exist, and a broad band between $3200-3400 \mathrm{~cm}^{-1}$ attributed to -O-H stretching vibration [52] appears in the FTIR spectrum of HDCNs. The band at $1672 \mathrm{~cm}^{-1}$ can be assigned to the $\mathrm{C}=\mathrm{O}$ stretching vibration from the residual NMP solvent in HDCNs [41]. The above results indicate that HDCNs are not fully cyclized at $120^{\circ} \mathrm{C}$. After vacuum drying $\left(120^{\circ} \mathrm{C}\right)$ and hot pressing at $150{ }^{\circ} \mathrm{C}(0.3 \mathrm{MPa})$ for $1 \mathrm{~h}$, the band at $1672 \mathrm{~cm}^{-1}$ corresponding to the $\mathrm{C}=\mathrm{O}$ stretching vibration from the NMP solvent almost disappears in the FTIR spectrum of PHT (Figure 1c) [52]. It should be noted that the unexpected weak band at $3380 \mathrm{~cm}^{-1}$ attributed to the $-\mathrm{O}-\mathrm{H}$ stretching vibration may be due to the side reactions reported in the literature $[41,53]$. In addition, the band at $515 \mathrm{~cm}^{-1}$ assigned to the S-S stretching vibration is retained during the preparation of the PHT.

\subsection{Reprocessing and Healing of PHT}

The reported hexahydrotriazine-containing thermosets are degradable in acid solutions, but they cannot be reprocessed or healed [39-41,54]. Herein, the incorporated disulfide bonds, which can undergo bond exchange reactions at elevated temperature, endow the PHT with vitrimer features $[50,55,56]$. The PHT powders are able to be reprocessed into new coherent bulk specimens by hot pressing at $150{ }^{\circ} \mathrm{C}$ under $0.3 \mathrm{MPa}$ for $1 \mathrm{~h}$ (Figure 2a). This process can be repeated several times. The PHT is also healable, as shown in Figure $2 \mathrm{~b}$. A PHT bar with scratches can be easily healed by an electric iron or hot-press treatment using the above temperature. The mechanical properties of pristine and reprocessed PHTs were investigated by three-point bending tests. Figure $2 c$,d shows the representative flexural stress versus stain curves and flexural stress of pristine and reprocessed PHTs after different reprocessing cycles. As can be seen, the PHT exhibits good re-processability and two generations of reprocessed PHTs even show slightly increased average flexural stress when compared to the pristine PHT.

The thermomechanical properties of pristine and reprocessed PHTs were studied by dynamic mechanical analysis (DMA). The storage modulus and $\tan \delta$ versus temperature curves are shown in Figure 2e,f. Storage modulus can reflect the stiffness of polymer materials. The pristine and two reprocessed PHTs exhibit similar storage moduli ( 2890-2910 MPa) at room temperature, which are comparable to those of conventional thermosetting polymers such as epoxy resins. The temperature at the maximum $\tan \delta$ is regarded as the glass-transition temperature $\left(T_{\mathrm{g}}\right)$. It is shown that the $T_{\mathrm{g}} \mathrm{s}$ of reprocessed PHTs continuously decrease with the reprocessing cycles. Compared with the pristine PHT, the $T_{\mathrm{g}}$ of the second reprocessed PHT decreases from 135 to $117^{\circ} \mathrm{C}$. This might be because the 
disulfide bond, as a type of weak covalent bond, could be cleaved by oxidation during the hot-press treatment [2], leading to the decreased crosslinking density of reprocessed PHTs.

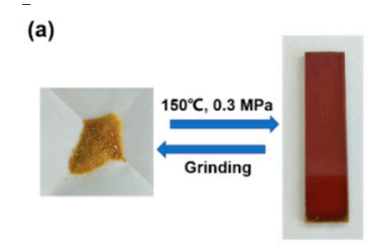

(b)

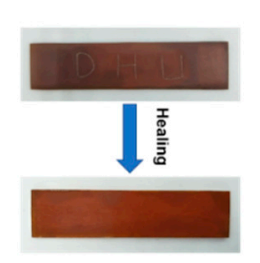

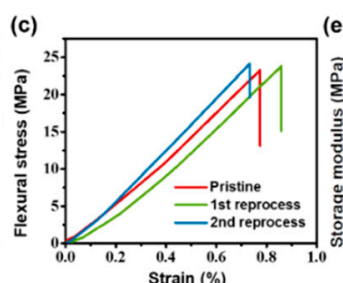
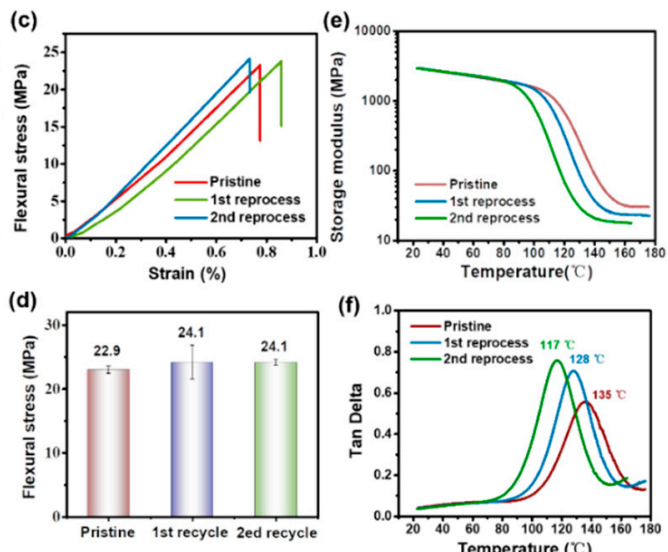

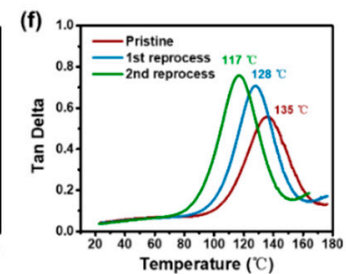

Figure 2. (a) Reversible reprocessing of the PHT. (b) A scratched PHT bar before and after healing. (c) Representative flexural stress versus strain curves (d) and flexural stress of pristine and reprocessed PHTs. (e) Storage modulus and (f) $\tan \delta$ versus temperature curves of pristine and reprocessed PHTs.

\subsection{Thermal Stress Relaxation}

As a CAN (or vitrimer), the dynamic structural characteristics of the PHT were studied by thermal stress relaxation tests. Figure 3a shows the normalized relaxation modulus $G_{(\mathrm{t})} / G_{0}$ of the PHT as a function of time at different temperatures. The PHT is able to relax the stress quickly when heated to more than $90^{\circ} \mathrm{C}$. The curves of stress relaxation are observed to cross at 100 and $110{ }^{\circ} \mathrm{C}$. This is because these two temperatures are both close to the onset region of the glass transition and the temperature difference is small. The PHT shows similar quick stress relaxation behaviors in the initial stage of the tests at 100 and $110^{\circ} \mathrm{C}$. A slight fluctuation of the DMA measurement might cause the cross of stress relaxation curves. Similar phenomena were also found for the reported vitrimers $[50,55,57]$. Following Maxwell's viscoelastic fluid model, the relaxation time $(\tau)$ is defined as the time when the sample is relaxed to 1/e of the initial modulus [8]. As can be seen, the stress relaxation of the PHT at $80{ }^{\circ} \mathrm{C}$ is slow, and the $\tau$ value at $80^{\circ} \mathrm{C}$ is estimated to be more than $2000 \mathrm{~s}$ by extrapolating the curve of the relaxation modulus versus time (Figure 3a). As expected, the $\tau$ values decrease with the elevation of temperature, owing to the increased exchange rate of disulfide bonds. The effect of temperature on the stress relaxation will be discussed at the end of this section. The activation energy $\left(E_{\mathrm{a}}\right)$ of disulfide bond exchange reactions can be calculated via Arrhenius' law [50,58], as shown in Equation (1).

$$
\tau(T)=\tau_{0} \exp \left(\frac{E_{a}}{R T}\right)
$$

where $\tau$ is the relaxation time, $\tau_{0}$ is the characteristic relaxation time at infinite temperature, $T$ is the testing temperature, and $R$ is the universal gas constant. The Arrhenius relationship of $\ln (\tau)$ versus 1000/T ( $T$ is the testing temperature) is shown in Figure $3 \mathrm{~b}$. The calculated $E_{\mathrm{a}}$ of disulfide bond exchange reactions is $61 \mathrm{~kJ} \mathrm{~mol}^{-1}$, which is comparable to that $\left(55 \mathrm{~kJ} \mathrm{~mol}^{-1}\right)$ of the disulfide-containing epoxy resin [50]. The $E_{\mathrm{a}}$ of the PHT is lower than many reported vitrimers containing other dynamic covalent bonds, such as ester, imine, carbamate, and triazolium [8,21,59-61].

Since the exchange reactions between disulfide bonds are temperature-dependent behaviors, the topology freezing transition temperature $\left(T_{\mathrm{v}}\right)$ is another important characteristic parameter for the PHT. $T_{\mathrm{v}}$ is a hypothetical temperature at which vitrimers convert from solid to liquid and have a viscosity of $10^{12}$ Pa.s $[50,62]$. It is generally accepted that the crosslinking networks of vitrimers would 
be frozen when the temperature is below $T_{\mathrm{V}}$, owing to the low exchange reaction rate. The relaxation time $(\tau)$ at $T_{\mathrm{V}}$ can be calculated using Equation (2) [57].

$$
\eta=\frac{1}{3} E^{\prime} \tau
$$

where $E^{\prime}$ is the plateau modulus in the rubber region from the DMA curve (Figure 2e) and $\eta$ is the viscosity at $T_{v}$ (i.e., 1012 Pa.s). The calculated $\tau$ (at $T_{v}$ ) was applied to the Arrhenius' fitted line (Figure $3 \mathrm{~b}$ ) to obtain $T_{v}$. The $T_{v}$ of the PHT is $-85.7^{\circ} \mathrm{C}$, which is consistent with the fact that the exchange reactions between aromatic disulfides can occur at room temperature [42]. It is noteworthy that the disulfide exchange reactions in the PHT networks are also determined by the segmental mobility related to $T_{g}$. In general, it is believed that large-scale coordinated motions of the polymer chains occur in the glass transition region. When the PHT is in the glassy state, the disulfide bonds in the PHT would have very low contact probability. However, a slow stress relaxation of the PHT is observed at $80^{\circ} \mathrm{C}$, which is below its $T_{g}\left(135^{\circ} \mathrm{C}\right)$, as shown in Figure 3a. Similar stress relaxation below the $T_{g}$ of the vitrimer was also reported by Zhao and his co-workers [63]. This indicates the bond exchange reactions between the dynamic covalent bonds in the vitrimer could occur and cause stress relaxation even if the motion of polymer chains is slow. The polymer chains of the PHT should already have certain mobility at $80^{\circ} \mathrm{C}$ to facilitate the disulfide bond exchange reactions. Considering that the $T_{g}\left(135^{\circ} \mathrm{C}\right)$ of the PHT is much higher than its $T_{v}$, the stress relaxation phenomenon is dominated by $T_{g}$ and, thus, gradually becomes pronounced as the temperature approaches $T_{g}$.
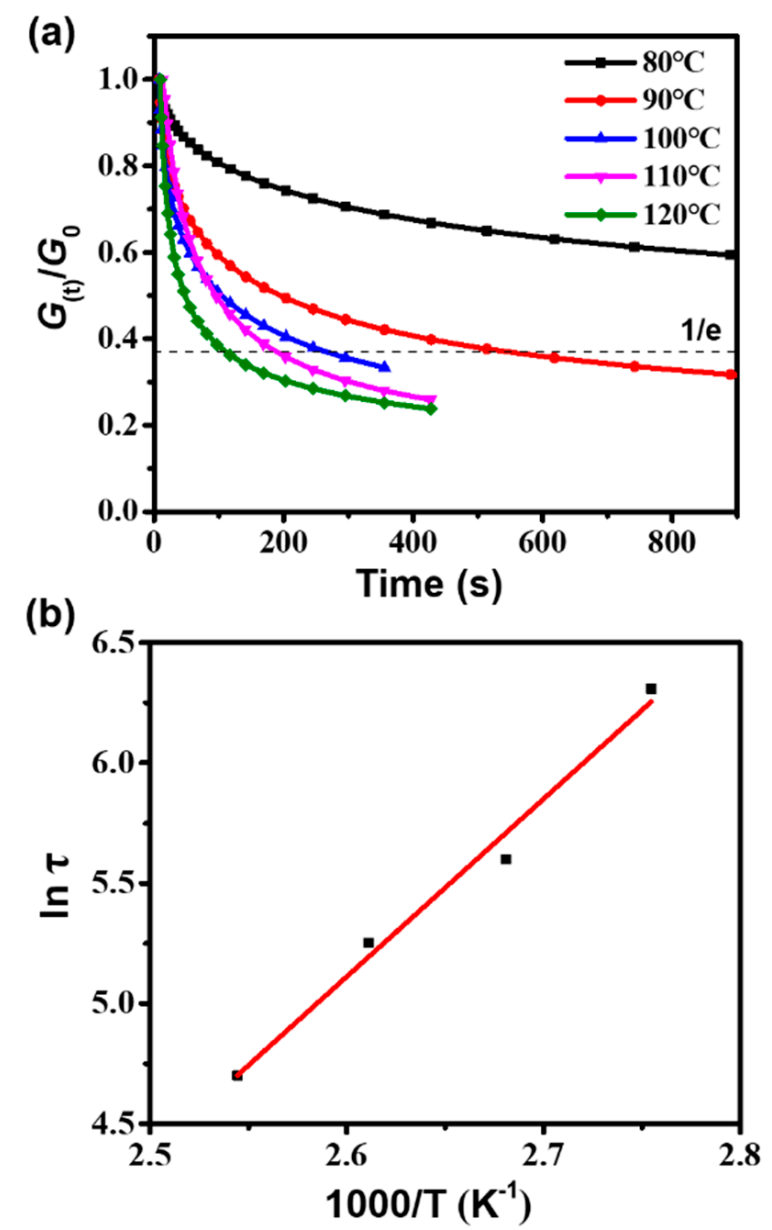

Figure 3. (a) Normalized relaxation modulus as a function of time of the polyhexahydrotriazine thermoset (PHT) at different temperatures. (b) The Arrhenius fitted line between $\ln (\tau)$ and 1000/T. 


\subsection{Reworkability and Solvent Resistance}

Reworkable thermosetting polymers mean they can be thoroughly removed by structure break-down under controlled external stimulus, such as chemical or heat treatments $[2,4,64]$. To endow thermosetting polymers with re-workability, a well-established strategy is to introduce chemicallyor thermally-labile groups [2]. It has been reported that the hexahydrotriazine ring tends to degrade in the aqueous acid solution $[41,54]$, and the disulfide bond can react with thiols through the bond exchange reaction $[50,65]$. To examine the chemical reworkability of the PHT, two pieces of PHT samples were immersed in 2-mercaptoethanol/DMF (0.1M) and $\mathrm{HCl}(1 \mathrm{M})$ solutions, respectively. As shown in Figure 4a, the PHT could be entirely dissolved in the thiol solution, which turned pale yellow after standing for $24 \mathrm{~h}$ at room temperature. The PHT was disintegrated into powders and partially dissolved the $\mathrm{HCl}$ solution at the same condition. The PHT is more liable to degrade in the thiol solution, which is consistent with the low $E_{a}$ of disulfide bond exchange reactions.

(a)

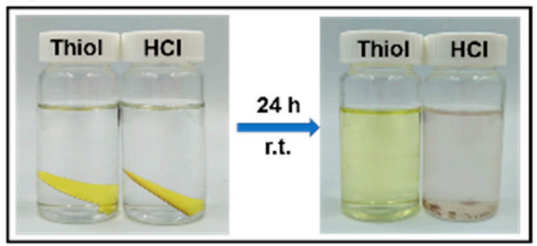

(b)

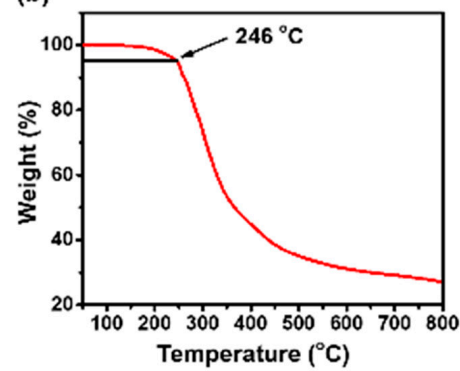

(c)

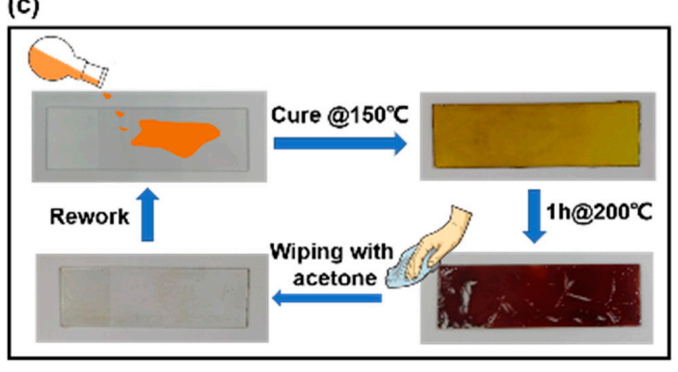

Figure 4. (a) Chemical degradation of the PHT in 2-mercaptoethanol/DMF and $\mathrm{HCl}(1 \mathrm{M})$ solutions. (b) TGA curve of the PHT under a nitrogen atmosphere. (c) Thermal re-workability of the PHT at $200{ }^{\circ} \mathrm{C}$ for $1 \mathrm{~h}$.

It has been reported that thermally reworkable thermosetting polymers for electronic packaging applications are desirable to decompose at a temperature around $220^{\circ} \mathrm{C}$ [66]. The thermal stability of the PHT was investigated by TGA (Figure $4 \mathrm{~b}$ ). The PHT starts to decompose at $246^{\circ} \mathrm{C}$ ( $5 \%$ weight loss) at a heat rate of $10^{\circ} \mathrm{C} \mathrm{min}-1$. To demonstrate its thermal reworkability, the PHT was cured on a glass slide. After heating at $200{ }^{\circ} \mathrm{C}$ for $1 \mathrm{~h}$, the PHT decomposed and the dark brown residue on the glass slide could be conveniently wiped off using a piece of cloth soaked by acetone (Figure 4c). The above demonstrations suggest that the PHT can be reworked by both chemical and thermal methods.

The thermal degradation of the PHT at $200{ }^{\circ} \mathrm{C}$ was studied by analysing the structure of the residue by FTIR (Figure 5a). The bands attributed to the stretching vibration of benzene ring (1580 and $1485 \mathrm{~cm}^{-1}$ ) are used as internal references. Compared with the pristine PHT, the band intensity of S-S stretching vibration $\left(515 \mathrm{~cm}^{-1}\right)$ clearly decreases in the FTIR spectrum of the PHT residue, indicating the cleavage of disulfide bonds. This is consistent with the lower low bond dissociation energy $(210-270 \mathrm{~kJ} / \mathrm{mol})$ of disulfide bonds [47,48]. In addition, it has been reported that there might exist some weak chemical bonds in the PHT (such as tertiary amine-containing ether linkages), which could also make the PHT start to degrade at around $200{ }^{\circ} \mathrm{C}$ [41]. Considering the lower degradation temperature of the PHT, it is essential to verify the structure of the reprocessed PHT after the hot-press treatment $\left(150{ }^{\circ} \mathrm{C}, 0.3 \mathrm{MPa}\right)$ adopted in this work. Compared with the pristine PHT, no significant changes are observed in the FTIR spectrum of the reprocessed PHT, and the band $\left(515 \mathrm{~cm}^{-1}\right)$ attributed 
to disulfide bonds is well maintained (Figure $5 b$ ). This indicates that disulfide bonds are not cleaved during the hot-press treatment. It is acceptable to reprocess the PHT at $150{ }^{\circ} \mathrm{C}$ based on the disulfide exchange reactions.
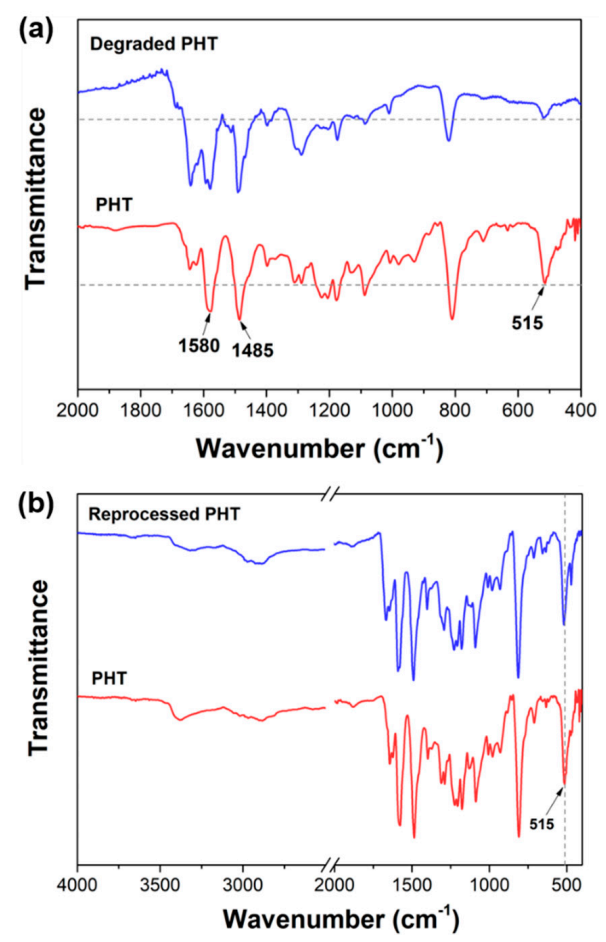

Figure 5. (a) FTIR spectra of the PHT and PHT residue after heating at $200{ }^{\circ} \mathrm{C}$. (b) FTIR spectra of the PHT and reprocessed PHT after the hot-press treatment at $150{ }^{\circ} \mathrm{C}$.

Owing to the chemical sensitivities of the hexahydrotriazine ring and disulfide bond, it is essential to evaluate the solvent resistance of the PHT. Figure 6 shows the photographs of PHT specimens immersed in $\mathrm{NaOH}(1 \mathrm{M})$, ethanol, acetone, THF, chloroform, NMP, and DMF for $120 \mathrm{~h}$ at room temperature. As can be observed, the PHT exhibits superior solvent resistance in the aqueous alkali solution and organic solvents except that a fraction is dissolved THF. This confirms that the degradation of the PHT has specific stimulus responsiveness. Like conventional thermosetting polymers, PHT is a suitable material for a range of applications.

(a)

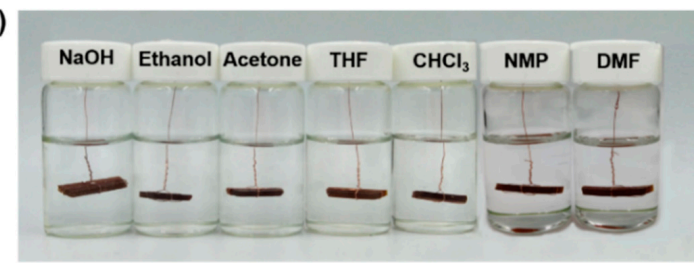

(b)

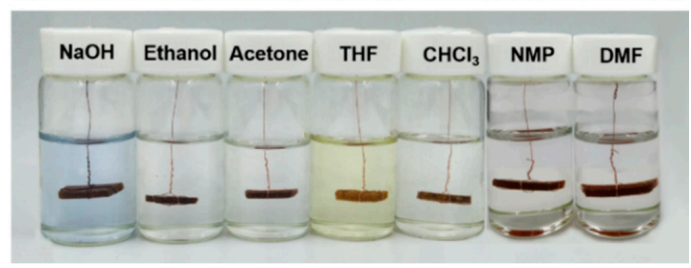

Figure 6. Photographs of the PHT in different solvents (a) before and (b) after standing for $120 \mathrm{~h}$ at room temperature. 


\subsection{Mechanochromism}

Interestingly, the PHT shows reversible mechanochromic behaviors, as shown in Figure 7a. The PHT powders could transiently turn from golden yellow to green when hit using a hammer. The colour of the PHT would totally recover after heating at $150{ }^{\circ} \mathrm{C}$ only for $1 \mathrm{~min}$. When the PHT resin was hit again, its colour turned green accordingly. It is worth noting that only breaking is able to induce this mechanochromic effect, while stretching or bending the PHT will not cause any colour changes. It was proposed that the green coloration was related to the formation of sulfenyl radicals generated from the mechanical cleavage of disulfide bonds (Figure 7b) [49]. Although these sulfenyl radicals are quite reactive, they can be "frozen" and survive for a certain time when the temperature is far below the $T_{\mathrm{g}}$. As the segmental mobility increases at high temperature, these sulfenyl radicals tend to pair up to disulfide bonds again, resulting in the colour recovery. Therefore, the PHT has the inherent self-monitoring function for mechanical damages.

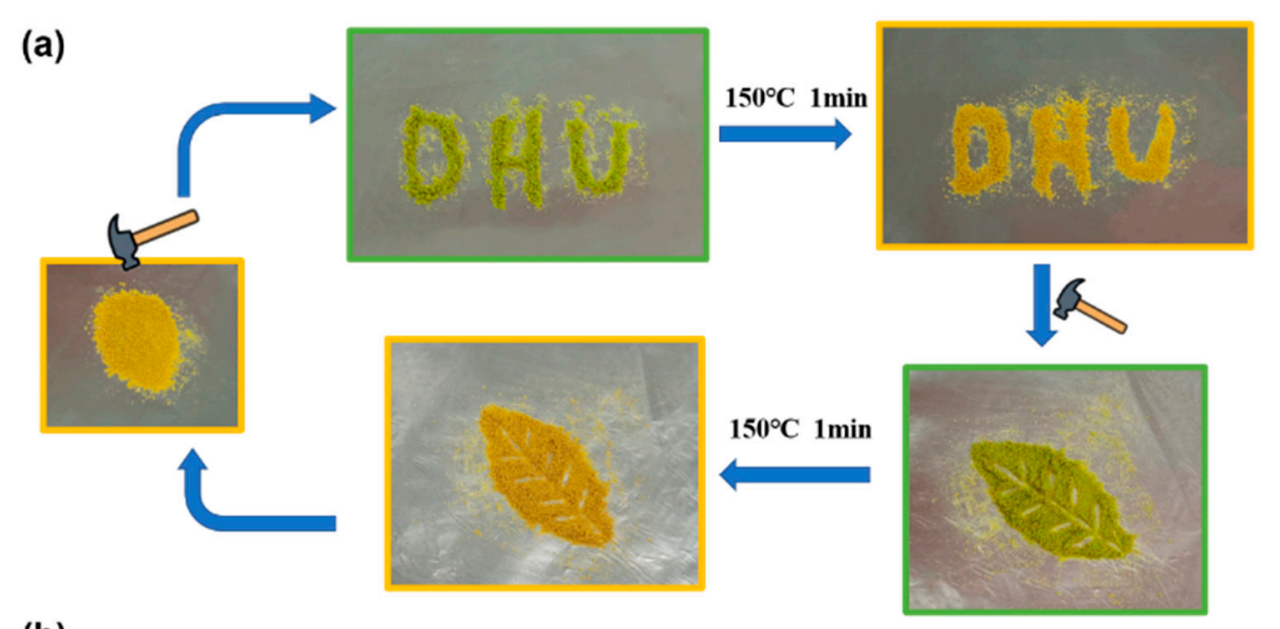

(b)

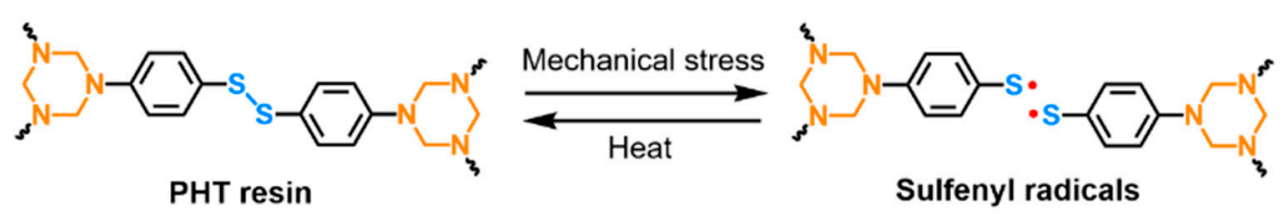

Figure 7. (a) Reversible mechanochromic behaviors of the PHT. (b) A schematic illustration of the generation and coupling of sulfenyl radicals in the PHT networks.

\section{Conclusions}

In summary, we report a disulfide-containing PHT with a combination of recyclability, re-workability, and damage monitoring function. The PHT can be reprocessed like thermoplastics by hot pressing. Notably, the reprocessed PHTs exhibit almost a full recovery of flexural strength even after two reprocessing cycles. The results of stress relaxation tests indicate that the PHT has lower bond exchange activation energy $\left(61 \mathrm{~kJ} \mathrm{~mol}^{-1}\right)$ and topology freezing transition temperature $\left(-85.7^{\circ} \mathrm{C}\right)$ due to the dynamic feature of disulfide bonds. The PHT can be reworked by both chemical and thermal manners. The PHT is liable to degrade in the mild aqueous acid and thiol solutions at room temperature, but shows good resistance to many conventional organic solvents. The removal test demonstrates that the residuals from the decomposed PHT $\left(200{ }^{\circ} \mathrm{C}\right.$ for $\left.1 \mathrm{~h}\right)$ can be easily removed by acetone. Finally, the PHT shows reversible mechanochromic behaviors due to the generation and coupling of sulfenyl radicals. It is foreseen that the simple preparation and multiple functions make the PHT have great potential for a variety of applications, such as electronic encapsulation and fiber-reinforced polymer composites. 
Author Contributions: Conceptualization, W.L.; formal analysis, S.Z. and I.T.; investigation, L.C.; resources, Q.J., Y.W. and Y.Q.; data curation, L.C. and S.Z.; writing-original draft preparation, L.C.; writing-review and editing, I.T., Q.J., Y.W. and W.L.; funding acquisition, W.L. All authors have read and agreed to the published version of the manuscript.

Funding: This research was supported by the Natural Science Foundation of Shanghai (18ZR1400700) and Fundamental Research Funds for the Central Universities (2232019D3-48)

Acknowledgments: The authors would like to acknowledge Liying Zhang for sharing the hot-press equipment for this work.

Conflicts of Interest: The authors declare no conflict of interest.

\section{References}

1. Garcia, J.M.; Robertson, M.L. The future of plastics recycling Chemical advances are increasing the proportion of polymer waste that can be recycled. Science 2017, 358, 870-872. [CrossRef] [PubMed]

2. Ma, S.; Webster, D.C. Degradable thermosets based on labile bonds or linkages: A review. Prog. Polym. Sci. 2018, 76, 65-110. [CrossRef]

3. Denissen, W.; Winne, J.M.; Du Prez, F.E. Vitrimers: Permanent organic networks with glass-like fluidity. Chem. Sci. 2016, 7, 30-38. [CrossRef] [PubMed]

4. Wang, L.; Wong, C.P. Syntheses and characterizations of thermally reworkable epoxy resins. Part I. J. Polym. Sci. A Polym. Chem. 1999, 37, 2991-3001. [CrossRef]

5. Chen, X.X.; Dam, M.A.; Ono, K.; Mal, A.; Shen, H.B.; Nutt, S.R.; Sheran, K.; Wudl, F. A thermally re-mendable cross-linked polymeric material. Science 2002, 295, 1698-1702. [CrossRef]

6. Chakma, P.; Konkolewicz, D. Dynamic Covalent Bonds in Polymeric Materials. Angew. Chem. Int. Edit. 2019, 58, 9682-9695. [CrossRef]

7. Taynton, P.; Yu, K.; Shoemaker, R.K.; Jin, Y.H.; Qi, H.J.; Zhang, W. Heat- or Water-Driven Malleability in a Highly Recyclable Covalent Network Polymer. Adv. Mater. 2014, 26, 3938-3942. [CrossRef]

8. Montarnal, D.; Capelot, M.; Tournilhac, F.; Leibler, L. Silica-Like Malleable Materials from Permanent Organic Networks. Science 2011, 334, 965-968. [CrossRef]

9. Wojtecki, R.J.; Meador, M.A.; Rowan, S.J. Using the dynamic bond to access macroscopically responsive structurally dynamic polymers. Nat. Mater. 2011, 10, 14-27. [CrossRef] [PubMed]

10. Scheutz, G.M.; Lessard, J.J.; Sims, M.B.; Sumerlin, B.S. Adaptable Crosslinks in Polymeric Materials: Resolving the Intersection of Thermoplastics and Thermosets. J. Am. Chem Soc. 2019, 141, 16181-16196. [CrossRef] [PubMed]

11. Kloxin, C.J.; Bowman, C.N. Covalent adaptable networks: Smart, reconfigurable and responsive network systems. Chem Soc. Rev. 2013, 42, 7161-7173. [CrossRef] [PubMed]

12. Chakma, P.; Digby, Z.A.; Via, J.; Shulman, M.P.; Sparks, J.L.; Konkolewicz, D. Tuning thermoresponsive network materials through macromolecular architecture and dynamic thiol-Michael chemistry. Polym. Chem. 2018, 9, 4744-4756. [CrossRef]

13. De Alwis Watuthanthrige, N.; Ahammed, B.; Dolan, M.T.; Fang, Q.; Wu, J.; Sparks, J.L.; Zanjani, M.B.; Konkolewicz, D.; Ye, Z. Accelerating dynamic exchange and self-healing using mechanical forces in crosslinked polymers. Mater. Horiz. 2020, 7, 1581-1587. [CrossRef]

14. Ishibashi, J.S.A.; Kalow, J.A. Vitrimeric Silicone Elastomers Enabled by Dynamic Meldrum's Acid-Derived Cross-Links. ACS Macro Lett. 2018, 7, 482-486. [CrossRef]

15. Chakma, P.; Morley, C.N.; Sparks, J.L.; Konkolewicz, D. Exploring How Vitrimer-like Properties Can Be Achieved from Dissociative Exchange in Anilinium Salts. Macromolecules 2020, 53, 1233-1244. [CrossRef]

16. Fortman, D.J.; Brutman, J.P.; De Hoe, G.X.; Snyder, R.L.; Dichtel, W.R.; Hillmyer, M.A. Approaches to Sustainable and Continually Recyclable Cross-Linked Polymers. ACS Sustain. Chem. Eng. 2018, 6, 11145-11159. [CrossRef]

17. Zhao, G.; Zhou, Y.; Wang, J.; Wu, Z.; Wang, H.; Chen, H. Self-Healing of Polarizing Films via the Synergy between Gold Nanorods and Vitrimer. Adv. Mater. 2019, 31, e1900363. [CrossRef]

18. Chen, M.; Zhou, L.; Wu, Y.; Zhao, X.; Zhang, Y. Rapid Stress Relaxation and Moderate Temperature of Malleability Enabled by the Synergy of Disulfide Metathesis and Carboxylate Transesterification in Epoxy Vitrimers. ACS Macro Lett. 2019, 8, 255-260. [CrossRef] 
19. Zhang, Y.; Yuan, L.; Liang, G.; Gu, A. Developing Reversible Self-Healing and Malleable Epoxy Resins with High Performance and Fast Recycling through Building Cross-Linked Network with New DisulfideContaining Hardener. Ind. Eng. Chem. Res. 2018, 57, 12397-12406. [CrossRef]

20. Liu, Y.; Tang, Z.; Chen, J.; Xiong, J.; Wang, D.; Wang, S.; Wu, S.; Guo, B. Tuning the mechanical and dynamic properties of imine bond crosslinked elastomeric vitrimers by manipulating the crosslinking degree. Polym. Chem. 2020, 11, 1348-1355. [CrossRef]

21. Memon, H.; Liu, H.Y.; Rashid, M.A.; Chen, L.; Jiang, Q.R.; Zhang, L.Y.; Wei, Y.; Liu, W.S.; Qiu, Y.P. Vanillin-Based Epoxy Vitrimer with High Performance and Closed-Loop Recyclability. Macromolecules 2020, 53, 621-630. [CrossRef]

22. Shen, Y.; Xu, N.; Adraro, Y.A.; Wang, B.; Liu, Y.; Yuan, W.; Xu, X.; Huang, Y.; Hu, Z. Imine or Secondary Amine-Derived Degradable Polyaminal: Low-Cost Matrix Resin with High Performance. ACS Sustain. Chem. Eng. 2020, 8, 1943-1953. [CrossRef]

23. Hao, C.; Liu, T.; Zhang, S.; Liu, W.; Shan, Y.; Zhang, J. Triethanolamine-Mediated Covalent Adaptable Epoxy Network: Excellent Mechanical Properties, Fast Repairing, and Easy Recycling. Macromolecules 2020, 53, 3110-3118. [CrossRef]

24. Liu, T.; Zhao, B.; Zhang, J. Recent development of repairable, malleable and recyclable thermosetting polymers through dynamic transesterification. Polymer 2020, 194, 122392. [CrossRef]

25. Wu, J.; Yu, X.; Zhang, H.; Guo, J.; Hu, J.; Li, M.-H. Fully Biobased Vitrimers from Glycyrrhizic Acid and Soybean Oil for Self-Healing, Shape Memory, Weldable, and Recyclable Materials. ACS Sustain. Chem. Eng. 2020, 8, 6479-6487. [CrossRef]

26. Lu, Y.X.; Guan, Z. Olefin metathesis for effective polymer healing via dynamic exchange of strong carbon-carbon double bonds. J. Am. Chem Soc. 2012, 134, 14226-14231. [CrossRef]

27. Lu, Y.X.; Tournilhac, F.; Leibler, L.; Guan, Z. Making insoluble polymer networks malleable via olefin metathesis. J. Am. Chem Soc. 2012, 134, 8424-8427. [CrossRef]

28. Tretbar, C.A.; Neal, J.A.; Guan, Z. Direct Silyl Ether Metathesis for Vitrimers with Exceptional Thermal Stability. J. Am. Chem Soc. 2019, 141, 16595-16599. [CrossRef]

29. Zych, A.; Pinalli, R.; Soliman, M.; Vachon, J.; Dalcanale, E. Polyethylene vitrimers via silyl ether exchange reaction. Polymer 2020, 199, 122567. [CrossRef]

30. Christensen, P.R.; Scheuermann, A.M.; Loeffler, K.E.; Helms, B.A. Closed-loop recycling of plastics enabled by dynamic covalent diketoenamine bonds. Nat. Chem 2019, 11, 442-448. [CrossRef]

31. He, C.; Christensen, P.R.; Seguin, T.J.; Dailing, E.A.; Wood, B.M.; Walde, R.K.; Persson, K.A.; Russell, T.P.; Helms, B.A. Conformational Entropy as a Means to Control the Behavior of Poly(diketoenamine) Vitrimers In and Out of Equilibrium. Angew. Chem. Int. Ed. Engl. 2020, 59, 735-739. [CrossRef] [PubMed]

32. Caffy, F.; Nicolaÿ, R. Transformation of polyethylene into a vitrimer by nitroxide radical coupling of a bis-dioxaborolane. Polym. Chem. 2019, 10, 3107-3115. [CrossRef]

33. Ricarte, R.G.; Tournilhac, F.; Cloître, M.; Leibler, L. Linear Viscoelasticity and Flow of Self-Assembled Vitrimers: The Case of a Polyethylene/Dioxaborolane System. Macromolecules 2020, 53, 1852-1866. [CrossRef]

34. Chen, Q.; Qian, X.; Xu, Y.; Yang, Y.; Wei, Y.; Ji, Y. Harnessing the Day-Night Rhythm of Humidity and Sunlight into Mechanical Work Using Recyclable and Reprogrammable Soft Actuators. ACS Appl. Mater. Interfaces 2019, 11, 29290-29297. [CrossRef]

35. Miao, J.T.; Ge, M.; Peng, S.; Zhong, J.; Li, Y.; Weng, Z.; Wu, L.; Zheng, L. Dynamic Imine Bond-Based Shape Memory Polymers with Permanent Shape Reconfigurability for 4D Printing. ACS Appl. Mater. Interfaces 2019, 11, 40642-40651. [CrossRef]

36. Feng, Z.; Hu, J.; Zuo, H.; Ning, N.; Zhang, L.; Yu, B.; Tian, M. Photothermal-Induced Self-Healable and Reconfigurable Shape Memory Bio-Based Elastomer with Recyclable Ability. ACS Appl Mater. Interfaces 2019, 11, 1469-1479. [CrossRef]

37. Ji, F.; Liu, X.; Sheng, D.; Yang, Y. Epoxy-vitrimer composites based on exchangeable aromatic disulfide bonds: Reprocessibility, adhesive, multi-shape memory effect. Polymer 2020, 197, 122514. [CrossRef]

38. Huang, Z.; Wang, Y.; Zhu, J.; Yu, J.; Hu, Z. Surface engineering of nanosilica for vitrimer composites. Compos. Sci. Technol. 2018, 154, 18-27. [CrossRef]

39. Garcia, J.M.; Jones, G.O.; Virwani, K.; McCloskey, B.D.; Boday, D.J.; ter Huurne, G.M.; Horn, H.W.; Coady, D.J.; Bintaleb, A.M.; Alabdulrahman, A.M.S.; et al. Recyclable, Strong Thermosets and Organogels via Paraformaldehyde Condensation with Diamines. Science 2014, 344, 732-735. [CrossRef] 
40. Kaminker, R.; Callaway, E.B.; Dolinski, N.D.; Barbon, S.M.; Shibata, M.; Wang, H.; Hu, J.; Hawker, C.J. Solvent-Free Synthesis of High-Performance Polyhexahydrotriazine (PHT) Thermosets. Chem. Mater. 2018, 30, 8352-8358. [CrossRef]

41. Yuan, Y.; Sun, Y.; Yan, S.; Zhao, J.; Liu, S.; Zhang, M.; Zheng, X.; Jia, L. Multiply fully recyclable carbon fibre reinforced heat-resistant covalent thermosetting advanced composites. Nat. Commun. 2017, 8, 14657. [CrossRef] [PubMed]

42. Matxain, J.M.; Asua, J.M.; Ruiperez, F. Design of new disulfide-based organic compounds for the improvement of self-healing materials. Phys. Chem. Chem. Phys. 2016, 18, 1758-1770. [CrossRef] [PubMed]

43. Wang, B.; Ma, S.; Yan, S.; Zhu, J. Readily recyclable carbon fiber reinforced composites based on degradable thermosets: A review. Green Chem. 2019, 21, 5781-5796. [CrossRef]

44. Yoon, J.A.; Kamada, J.; Koynov, K.; Mohin, J.; Nicolay, R.; Zhang, Y.Z.; Balazs, A.C.; Kowalewski, T.; Matyjaszewski, K. Self-Healing Polymer Films Based on Thiol-Disulfide Exchange Reactions and Self-Healing Kinetics Measured Using Atomic Force Microscopy. Macromolecules 2012, 45, 142-149. [CrossRef]

45. Tsarevsky, N.V.; Matyjaszewski, K. Reversible redox cleavage/coupling of polystyrene with disulfide or thiol groups prepared by atom transfer radical polymerization. Macromolecules 2002, 35, 9009-9014. [CrossRef]

46. Rekondo, A.; Martin, R.; de Luzuriaga, A.R.; Cabanero, G.; Grande, H.J.; Odriozola, I. Catalyst-free room-temperature self-healing elastomers based on aromatic disulfide metathesis. Mater. Horiz.s 2014, 1, 237-240. [CrossRef]

47. Takahashi, A.; Ohishi, T.; Goseki, R.; Otsuka, H. Degradable epoxy resins prepared from diepoxide monomer with dynamic covalent disulfide linkage. Polymer 2016, 82, 319-326. [CrossRef]

48. Denes, F.; Pichowicz, M.; Povie, G.; Renaud, P. Thiyl Radicals in Organic Synthesis. Chem Rev. 2014, 114, 2587-2693. [CrossRef]

49. Ruiz de Luzuriaga, A.; Matxain, J.M.; Ruipérez, F.; Martin, R.; Asua, J.M.; Cabañero, G.; Odriozola, I. Transient mechanochromism in epoxy vitrimer composites containing aromatic disulfide crosslinks. J. Mater. Chem. C 2016, 4, 6220-6223. [CrossRef]

50. Ruiz de Luzuriaga, A.; Martin, R.; Markaide, N.; Rekondo, A.; Cabañero, G.; Rodríguez, J.; Odriozola, I. Epoxy resin with exchangeable disulfide crosslinks to obtain reprocessable, repairable and recyclable fiber-reinforced thermoset composites. Mater. Horiz. 2016, 3, 241-247. [CrossRef]

51. Lei, H.; Wang, S.; Liaw, D.J.; Cheng, Y.; Yang, X.; Tan, J.; Chen, X.; Gu, J.; Zhang, Y. Tunable and Processable Shape-Memory Materials Based on Solvent-Free, Catalyst-Free Polycondensation between Formaldehyde and Diamine at Room Temperature. ACS Macro Lett. 2019, 8, 582-587. [CrossRef]

52. Yang, Z.H.; Duan, C.J.; Sun, Y.; Wang, T.M.; Zhang, X.R.; Wang, Q.H. Utilizing Polyhexahydrotriazine (PHT) to Cross-Link Polyimide Oligomers for High-Temperature Shape Memory Polymer. Ind. Eng. Chem. Res. 2019, 58, 10599-10608. [CrossRef]

53. Chen, Q.M.; Pei, Z.Q.; Xu, Y.S.; Li, Z.; Yang, Y.; Wei, Y.; Ji, Y. A durable monolithic polymer foam for efficient solar steam generation. Chem. Sci. 2018, 9, 623-628. [CrossRef] [PubMed]

54. You, S.; Ma, S.; Dai, J.; Jia, Z.; Liu, X.; Zhu, J. Hexahydro-s-triazine: A Trial for Acid-Degradable Epoxy Resins with High Performance. ACS Sustain. Chem. Eng. 2017, 5, 4683-4689. [CrossRef]

55. Zhou, F.; Guo, Z.; Wang, W.; Lei, X.; Zhang, B.; Zhang, H.; Zhang, Q. Preparation of self-healing, recyclable epoxy resins and low-electrical resistance composites based on double-disulfide bond exchange. Compos. Sci. Technol. 2018, 167, 79-85. [CrossRef]

56. Azcune, I.; Odriozola, I. Aromatic disulfide crosslinks in polymer systems: Self-healing, reprocessability, recyclability and more. Eur. Polym. J. 2016, 84, 147-160. [CrossRef]

57. Zhang, L.; Rowan, S.J. Effect of Sterics and Degree of Cross-Linking on the Mechanical Properties of Dynamic Poly(alkylurea-urethane) Networks. Macromolecules 2017, 50, 5051-5060. [CrossRef]

58. Liu, T.; Hao, C.; Wang, L.; Li, Y.; Liu, W.; Xin, J.; Zhang, J. Eugenol-Derived Biobased Epoxy: Shape Memory, Repairing, and Recyclability. Macromolecules 2017, 50, 8588-8597. [CrossRef]

59. Obadia, M.M.; Mudraboyina, B.P.; Serghei, A.; Montarnal, D.; Drockenmuller, E. Reprocessing and Recycling of Highly Cross-Linked Ion-Conducting Networks through Transalkylation Exchanges of C-N Bonds. J. Am. Chem Soc. 2015, 137, 6078-6083. [CrossRef]

60. Fortman, D.J.; Brutman, J.P.; Cramer, C.J.; Hillmyer, M.A.; Dichtel, W.R. Mechanically Activated, Catalyst-Free Polyhydroxyurethane Vitrimers. J. Am. Chem Soc. 2015, 137, 14019-14022. [CrossRef]

61. Brutman, J.P.; Delgado, P.A.; Hillmyer, M.A. Polylactide Vitrimers. Acs Macro Lett. 2014, 3, 607-610. [CrossRef] 
62. Dyre, J.C. Colloquium: The glass transition and elastic models of glass-forming liquids. Rev. Mod. Phys. 2006, 78, 953-972. [CrossRef]

63. Zhao, S.; Abu-Omar, M.M. Recyclable and Malleable Epoxy Thermoset Bearing Aromatic Imine Bonds. Macromolecules 2018, 51, 9816-9824. [CrossRef]

64. Yang, S.; Chen, J.S.; Korner, H.; Breiner, T.; Ober, C.K.; Poliks, M.D. Reworkable epoxies: Thermosets with thermally cleavable groups for controlled network breakdown. Chem. Mater. 1998, 10, 1475-1482. [CrossRef]

65. Johnson, L.M.; Ledet, E.; Huffman, N.D.; Swarner, S.L.; Shepherd, S.D.; Durham, P.G.; Rothrock, G.D. Controlled degradation of disulfide-based epoxy thermosets for extreme environments. Polymer 2015, 64, 84-92. [CrossRef]

66. Wang, L.J.; Li, H.Y.; Wong, C.P. Syntheses and characterizations of thermally reworkable epoxy resins II. J. Polym Sci. A Polym. Chem. 2000, 38, 3771-3782. [CrossRef]

Publisher's Note: MDPI stays neutral with regard to jurisdictional claims in published maps and institutional affiliations.

(C) 2020 by the authors. Licensee MDPI, Basel, Switzerland. This article is an open access article distributed under the terms and conditions of the Creative Commons Attribution (CC BY) license (http://creativecommons.org/licenses/by/4.0/). 